\title{
Validating Star-Oddi heart rate and acceleration data storage tags for use in Atlantic salmon (Salmo salar)
}

\author{
Zoe Amanda Zrini" (ID and A. Kurt Gamperl
}

\begin{abstract}
Background: Data storage tags (DSTs) record and store information about animals and their environment, and can provide important data relevant to fish culture, ecology and conservation. A DST has recently been developed that records heart rate $\left(f_{H}\right)$, electrocardiograms (ECGs), tri-axial acceleration and temperature. However, at the time of this study, no research using these tags had been performed on fish or determined the quality of the data collected. Thus, our research asked: do these DSTs provide reliable and meaningful data? To examine this question, Atlantic salmon $(1.4 \pm 0.7 \mathrm{~kg})$ were implanted with DSTs, then swam at increasing speeds in a swim tunnel after 1 week of recovery. Further, in two separate experiments, salmon $(2.4 \pm 0.1 \mathrm{~kg})$ were implanted with DSTs and held in a large tank with conspecifics for 1 week at $11^{\circ} \mathrm{C}$ or 6 weeks at $8-12^{\circ} \mathrm{C}$.

Results: External acceleration (EA) and variation in EA (VAR) increased exponentially with swimming speed and tail beat frequency. The quality index $\left(\mathrm{Q} I\right.$ ) assigned to $\mathrm{ECG}$ recordings (where $\mathrm{Ql}_{0}$ means very good quality, and $\mathrm{Ql}_{1}, \mathrm{Ql}_{2}$ and $\mathrm{QI}_{3}$ are of reduced quality) did not change significantly with increasing swimming speed $\left(\mathrm{QI}_{0} \sim 60-80 \%\right)$. However, we found that the accuracy of the tag algorithm in estimating $f_{H}$ from ECGs was reduced when $\mathrm{QI}_{>0}$. Diurnal patterns of $f_{H}$ and $E A$ were evident from the time the salmon were placed in the tank. Heart rate appeared to stabilize by $\sim 4$ days post-surgery in the first experiment, but extended holding showed that $f_{H}$ declined for $2-3$ weeks. During extended holding, the tag had difficulty recording low $f_{\mathrm{H}}$ values $<30 \mathrm{bpm}$, and for this reason, in addition to the fact that the algorithm can miscalculate $f_{\mathrm{H}}$, it is highly recommended that ECGs be saved when possible for quality control and so that $f_{\mathrm{H}}$ values with $\mathrm{QI}_{>0}$ can be manually calculated.

Conclusions: With these DSTs, parameters of acceleration can be used to monitor the activity of free-swimming salmon. Further, changes in $f_{\mathrm{H}}$ and heart rate variability (HRV) due to diurnal rhythms, and in response to temperature, activity and stressors, can be recorded.
\end{abstract}

Keywords: Data storage tags, Atlantic salmon, Heart rate, Surgical recovery, Acceleration, Swimming speed, Calibration

\section{Background}

The monitoring of physiology and behavior allows researchers to study how animals cope with changes in environmental conditions, including those associated

\footnotetext{
*Correspondence: zoezrini@gmail.com
}

Department of Ocean Sciences, Memorial University, St. John's, NL A1C 557 , Canada with global climate change $[1,2]$. Historically, the recording of biological data from free-ranging animals has been very difficult. However, the integration of electronic engineering and biology has led to the creation of biologging technologies [3, 4]. Data storage tags (DSTs) record highresolution data (at sampling frequencies up to or greater than $100 \mathrm{~Hz}$ depending on the parameter and tag) that are stored into the logger. Recently, DSTs have been

(c) The Author(s) 2021. This article is licensed under a Creative Commons Attribution 4.0 International License, which permits use, sharing, adaptation, distribution and reproduction in any medium or format, as long as you give appropriate credit to the original author(s) and the source, provide a link to the Creative Commons licence, and indicate if changes were made. The images or other third party material in this article are included in the article's Creative Commons licence, unless indicated otherwise in a credit line to the material. If material is not included in the article's Creative Commons licence and your intended use is not permitted by statutory regulation or exceeds the permitted use, you will need to obtain permission directly from the copyright holder. To view a copy of this licence, visit http://creativeco mmons.org/licenses/by/4.0/. The Creative Commons Public Domain Dedication waiver (http://creativecommons.org/publicdomain/ zero/1.0/) applies to the data made available in this article, unless otherwise stated in a credit line to the data. 
used to measure acceleration and heart rate $\left(f_{\mathrm{H}}\right)$ in fish, to estimate energy use [5-8], and to assess when fish are stressed [9-13]. Two types of DSTs that measure $f_{\mathrm{H}}$ exist: (1) heart rate recorders which detect and display the number of heart beats in a given sampling period; and (2) electrocardiogram (ECG) readers that record the electrical activity of the heart and store changes in cardiac electrical activity over the complete cardiac cycle (termed the 'complete PQRS profile') [14]. Heart rate DSTs have been used to address concerns about the conservation and welfare of both wild and cultured fish. For example, Donaldson et al. [15] used ECG loggers to examine the recovery of coho salmon (Oncorhynchus kisutch) from predator and fisheries encounters, and Prystay et al. [9] used $f_{\mathrm{H}}$ DSTs to study the effects of temperature on fisheries interactions in sockeye salmon (O. nerka). Recently, Brijs et al. $[11,12]$ used DSTs to examine the $f_{\mathrm{H}}$ (stress) response of cultured rainbow trout (O. mykiss) to common aquaculture practices.

Accelerometers also have the potential to inform conservation and management by providing information on the activity, behavior and energy use of free-swimming fish $[4,14,16]$. Acceleration loggers and transmitters record either partial or whole-animal body acceleration in one, two or three spatial axes with piezoelectric sensors that generate a voltage signal proportional to the acceleration experienced by the sensor [17]. In several salmonid species values of dynamic acceleration have been related to tail beat frequency and swimming speed $[18,19]$, and similar data have been used to classify types of behaviors (e.g., resting, routine and burst swimming) in male smallmouth bass (Micropterus dolomieu) [16] and to predict field metabolic rate and estimate energy use $[5,7]$. In addition, they have been used to inform fisheries management strategies and to provide information about the welfare of aquaculture species. For example, Brownscombe et al. [20] assessed the use of recovery bags when bonefish (Albula vulpes) angling, and Yasuda et al. [21] monitored field metabolism in net-caged red sea bream (Pagrus major).

Several companies are producing biologging equipment/sensors that require validation [14]. The new
centi-HRT ACT tag developed by Star-Oddi (Iceland) can simultaneously measure $f_{\mathrm{H}}$, ECGs, tri-axial acceleration and temperature (see https://www.star-oddi.com for specifics on recording capabilities). There are few tags available that simultaneously measure both physiological and behavioral parameters, and only one study exists in which a DST recorded both $f_{\mathrm{H}}$ and acceleration parameters in salmonids. Clark et al. [5] defined relationships between acceleration, $f_{\mathrm{H}}$, tail beat frequency, energy expenditure and swimming speed in free-swimming sockeye salmon. However, the data logger used in their study (iLogR, B.D. Taylor, La Trobe University, Melbourne, Australia) is not commercially available. While several studies have used Star-Oddi milli-HRT tags to measure $f_{\mathrm{H}}$ in fishes [9-13, 22], it is not currently known how accurate or effective the centi-HRT ACT tags are for monitoring the $f_{\mathrm{H}}$ and activity of free-swimming fish.

This paper evaluated the validity and reliability of centiHRT ACT tags for recording the physiology and behavior of free-swimming Atlantic salmon (Salmo salar) by addressing four questions. First, do the acceleration parameters calculated by the Star-Oddi algorithm provide meaningful estimates of swimming speed and tail beat frequency, and information on swimming behavior? Second, how long does it take fish to recover from the effects of surgery? Third, can the tags record subtle changes in fish physiology and behavior (e.g., diel patterns)? Finally, over long periods of time (i.e., weeks to months), does the initial tag placement/orientation change and do these tags continue to accurately record $f_{\mathrm{H}}$ and acceleration?

\section{Methods}

Data storage tag implantation/attachment

Several different types of DSTs were used in these experiments (see Table 1; and in Additional file 1: Table S1 for photographs).

The centi-HRT ACT and milli-HRT tags were first inserted into the tag-computer interface (COM-BOX) (this unit connected to a laptop computer), and the start time, start date and sampling intervals were set using Star-Oddi's Mercury software. These tags were then

Table 1 Specifications of the Star-Oddi data storage tags used in this study

\begin{tabular}{|c|c|c|c|c|c|}
\hline Tag type & Parameters & Experiment & Length (mm) & Diameter (mm) & Mass in air (g) \\
\hline Centi-HRT ACT & $f_{H}, E C G s$, acceleration, temperature & $\begin{array}{l}\#_{1}(n=8) \\
\#_{2}(n=10) \\
\#_{3}(n=8)\end{array}$ & 50 & 15 & 19 \\
\hline Milli-HRT & $f_{H}, E C G s$, temperature & $\#_{3}(n=2)$ & 42 & 13 & 12 \\
\hline Milli-TD & Pressure/depth, temperature & $\begin{array}{l}\#_{2}(n=10) \\
\#_{3}(n=4)\end{array}$ & 39.4 & 13 & 12 \\
\hline
\end{tabular}


prepared for implantation by tying two pieces of black, braided, non-absorbable and non-sterile silk suture (2-0) around the body of the tag at each end, after which these tags and the surgical equipment were cleaned thoroughly and sterilized in $70 \%$ ethanol. When milli-TD tags (which record depth and temperature; see Additional file 1: Fig. S1) were also being used, these tags were programmed using Star-Oddi's SeaStar software.

Previous studies have described methods for implanting tags into fish, and provided the basis for our study (e.g., see $[5,9])$. Fish were anaesthetized in seawater containing $0.2 \mathrm{~g} \mathrm{~L}^{-1}$ tricaine methanesulfonate (MS222). After losing equilibrium, the salmon were moved to a wetted surgical sponge where their gills were irrigated with aerated, $\sim 6^{\circ} \mathrm{C}$, seawater containing $0.1 \mathrm{~g} \mathrm{~L}^{-1}$ MS-222. Beginning at the posterior margin of the pectoral fins, a $\sim 3 \mathrm{~cm}$ mid-ventral incision was made through the skin and muscle using a scalpel. The centi-HRT ACT or milli-HRT tags were then inserted blunt end towards the posterior of the fish, and with the logger's electrodes facing the body wall (Fig. 1; Additional file 1: Table S1), and pulled forward so that they were located within $0.5 \mathrm{~cm}$ of the pericardium. The sutures attached to the tag were then passed through the body wall at the anterior and posterior margins of the incision using a curved surgical needle, and tied to hold the DST in place and to start closure of the incision. Finally, the remaining incision was closed using continuous stitches (2-0 silk) and super glue was applied to the incision and allowed to dry. In some fish (see "Experiment ${ }^{\#} 2$ : heart rate and 'activity' of free-swimming fish for 7 days post-surgery" and "Experiment ${ }^{\#} 3$ : heart rate, 'activity' and tag retention in free-swimming fish for 6 weeks post-surgery"), milliTD tags were then attached to the fish externally using a "plate holder kit" and stainless steel wire $(0.02$ " diameter). Information on the preparation and attachment of the milli-TD tags can be found in Additional file 1: Fig. S1. When the milli-TD tag was used in conjunction with the centi-HRT ACT tag, the combined mass in air was approx. $32 \mathrm{~g}$ (see Table 1 for a summary of the tags

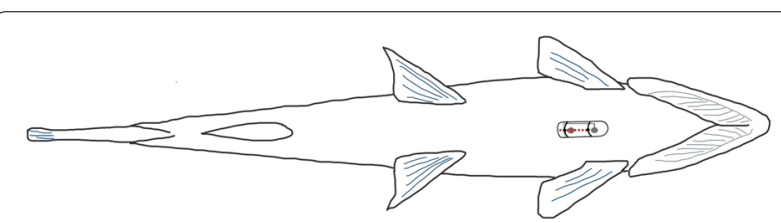

Fig. 1 Orientation and placement of the centi-HRT ACT and milli-HRT tags in Atlantic salmon. Based on preliminary studies, the electrodes of the tag were oriented towards the fish's body wall to produce good quality ECGs. Two pieces of 2-0 silk suture were tied around the tag to anchor it to the body wall and aid with closing the incision (red dotted line) used in each experiment). In all experiments, the tags did not exceed $2 \%$ of the fish's body mass, and therefore, the weight of the tags was not expected to disrupt fish behavior, growth or activity [23].

After surgery, the salmon were recovered in anesthetic-free water and returned to their holding tank (see below). Following all experiments, the fish were euthanized in seawater containing $0.3 \mathrm{~g} \mathrm{~L}^{-1} \mathrm{MS}-222$ to perform post-mortem dissections and to recover the tags/ data. Post-mortem dissections were conducted to record incision length, the distance from the front of the tag to the pericardium, any signs of infection or inflammation, and to determine the fish's sex when possible. Data were retrieved using the COM-BOX and Mercury software.

\section{Experiment ${ }^{\#} 1$ : relationship between accelerometry parameters and swimming speed}

The Atlantic salmon used in this experiment (range $\sim 0.94$ to $1.52 \mathrm{~kg}$ ) were held at the Ocean Science Centre in Logy Bay, Newfoundland, Canada. The fish were maintained in $2.2 \mathrm{~m}^{3}$ tanks supplied with seawater at $11-13{ }^{\circ} \mathrm{C}$ and $100-120 \%$ air saturation, and a $14 \mathrm{~h}$ light:10 h dark photoperiod. The fish were fed daily, the amount of feed $1.5 \times$ what they would eat in a single meal. This feed was provided by automatic feeders that distributed pellets every $30 \mathrm{~min}$ from 9:00 a.m. to 5:00 p.m.

These fish $(n=8 ; 1.35 \pm 0.74 \mathrm{~kg}, 46.70 \pm 0.79 \mathrm{~cm}$ in total length; mean \pm S.E.M.) were implanted with a centi-HRT $\mathrm{ACT}$ tag and returned to their tank to recover for 5 days. On the 6th day at 12:00 p.m., the pre-programmed centiHRT ACT tags began saving and recording ECGs $/ f_{\mathrm{H}}$ (at $100 \mathrm{~Hz}$ for $6 \mathrm{~s}$ ), tri-axial acceleration (at $1 \mathrm{~Hz}$ for $60 \mathrm{~s}$ ) and temperature every $2 \mathrm{~min}$. At 1:00 p.m., the fish were netted, lightly anaesthetized in seawater containing $0.1 \mathrm{~g} \mathrm{~L}^{-1} \mathrm{MS}-222$ and transferred to an $81 \mathrm{~L}$ Blazka-type swim tunnel $(25 \mathrm{~cm}$ diam., swimming section $120 \mathrm{~cm}$ in length). The swim tunnel was maintained at $\sim 11{ }^{\circ} \mathrm{C}$ by a temperature controlled, and aerated, external reservoir and set to a low current velocity ( $\sim 0.2$ body lengths $\mathrm{s}^{-1}$, $\left.\mathrm{BL} \mathrm{s}^{-1} ; \sim 10 \mathrm{~cm} \mathrm{~s}^{-1}\right)$. This allowed the fish to rest on the bottom of the swim tunnel and maintain an upright position without swimming. The front of the swim tunnel was covered with black plastic to encourage the fish to seek refuge near the front of the tunnel.

At 11:00 a.m. the following day (i.e., after $21-22 \mathrm{~h}$ of acclimation), a critical swim speed $\left(U_{\text {crit }}\right)$ test was performed on the fish. Specifically, the water velocity was increased to $0.6 \mathrm{BL} \mathrm{s}^{-1}$ (a velocity at which the fish would start swimming), and then increased by $0.2 \mathrm{BL} \mathrm{s}^{-1}$ every 10 min until the fish fatigued and could no longer swim. When the fish's tail entered the back 1/6th of the tunnel, the back of the swim tunnel was tapped to encourage the fish to swim forward. In some cases $(n=5)$, after fish had 
reached their $U_{\text {crit }}$, they were given a short $(\sim 5 \mathrm{~min})$ rest period at low current velocity, then the water velocity was rapidly increased again to speeds above their $U_{\text {crit }}$. From these latter trials, only accelerometry data were used (i.e., $f_{\mathrm{H}}$ data were excluded).

The fish were continuously monitored during these swim trials, and only periods when fish were actively swimming were used in data analysis. Fish were given $1 \mathrm{~h}$ of recovery after the swim trial, then, they were removed from the swim tunnel and euthanized. At each swimming speed, video was recorded for $30 \mathrm{~s}$ from the side of the swim tunnel using a GoPro (Model HERO5; San Mateo, CA) mounted on a tri-pod. From these videos, the number of full tail oscillations in $10 \mathrm{~s}$ was recorded, and this value was multiplied by 6 to get the fish's tail beat frequency (TBF) in beats $\mathrm{min}^{-1}$. Three values were averaged to calculate the mean TBF of each fish at each swimming speed.

\section{Experiment " 2: heart rate and 'activity' of free-swimming fish for 7 days post-surgery}

Atlantic salmon (range $\sim 2.10$ to $2.95 \mathrm{~kg}$ ) were held at the Ocean Science Centre in a $2.64 \mathrm{~m}$ diameter $\times 2.50 \mathrm{~m}$ deep tank. This tank was supplied with seawater with a temperature and $\mathrm{O}_{2}$ level of $10-11^{\circ} \mathrm{C}$ and $100-120 \%$ of air saturation, respectively, and a $12 \mathrm{~h}$ light: $12 \mathrm{~h}$ dark photoperiod. The fish were fed a maintenance ration (1.0\% body mass) of commercial salmon diet every other day.

These fish $(n=10 ; 2.54 \pm 0.92 \mathrm{~kg} ; 62.23 \pm 1.00 \mathrm{~cm}$ in total length) were fitted with both centi-HRT ACT and milli-TD tags and returned to their tank to recover for 7 days with 30-35 conspecifics. Two fish were tagged weekly between January 18th and March 7th, 2018. The tags were pre-programmed to save and record ECGs $/ f_{\mathrm{H}}$ (at $100 \mathrm{~Hz}$ for $6 \mathrm{~s}$ ), tri-axial acceleration (at $1 \mathrm{~Hz}$ for $60 \mathrm{~s}$ ) and temperature every $10 \mathrm{~min}$, while the milli-TD tags were set to record depth and temperature every $1 \mathrm{~min}$. On the 7th day, the fish were netted from their tank and euthanized.

\section{Experiment ${ }^{\#} 3$ : heart rate, 'activity' and tag retention in free-swimming fish for 6 weeks post-surgery}

Atlantic salmon (range $~ 1.09$ to $3.25 \mathrm{~kg}$ ) were held at the Ocean Science Centre in a $2.64 \mathrm{~m}$ diameter by $3.78 \mathrm{~m}$ deep tank with a volume of $30 \mathrm{~m}^{3}$. This tank was supplied with seawater at $8-12{ }^{\circ} \mathrm{C}$ and with an $\mathrm{O}_{2}$ level of 100 $120 \%$ of air saturation, and a $12 \mathrm{~h}$ light: $12 \mathrm{~h}$ dark photoperiod, and the fish were fed a maintenance ration $(1.0 \%$ body mass) of commercial salmon diet on Mondays, Wednesdays and Fridays.

These fish $(2.27 \pm 0.25 \mathrm{~kg} ; 59.29 \pm 1.38 \mathrm{~cm}$ in total length) were implanted with both a centi-HRT ACT and a milli-TD tag $(n=4)$, a centi-HRT ACT tags alone $(n=4)$, or a milli-HRT tags alone $(n=2)$; the latter tag was provided by Star-Oddi for preliminary testing. Following implantation, the fish were held for 6 weeks with 20-25 conspecifics. Five fish were tagged on September 17th, 2018 and another 5 on December 12th, 2018. The centi-HRT ACT tags were pre-programmed to save and record ECGs $/ f_{\mathrm{H}}$ (at $100 \mathrm{~Hz}$ for $6 \mathrm{~s}$ ), tri-axial acceleration (at $1 \mathrm{~Hz}$ for $60 \mathrm{~s}$ ) and temperature every $2 \mathrm{~h}$, the milliHRT tags were set to store ECGs and record $f_{\mathrm{H}}$ (at $100 \mathrm{~Hz}$ for $6 \mathrm{~s}$ ) and temperature every $2 \mathrm{~h}$, and the milli-TD tags were set to record a depth and temperature every $1 \mathrm{~h}$. At the end of 6 weeks, the fish were netted from their tank and euthanized.

\section{Calculation of heart rate parameters}

All measurements of $f_{\mathrm{H}}$ were provided with a unitless measurement known as the quality index (QI) determined by the on-board tag algorithm. This parameter represents the quality of the ECG signal, where $\mathrm{QI}_{0}$ indicates that the recording was of very good quality, $\mathrm{QI}_{1}$ and $\mathrm{QI}_{2}$ indicate decreasing quality, and $\mathrm{QI}_{3}$ indicates that no $\mathrm{R}-\mathrm{R}$ interval was detected (i.e., the $\mathrm{R}$ peak in the PQRS complexes could not be clearly distinguished or two $R$ peaks were not present in the ECG (for a typical ECG recording see Additional file 1: Fig. S2). ECGs were stored (which is an option when programming the DSTs) in all experiments to allow for the manual calculation of $f_{\mathrm{H}}$. In Experiment ${ }^{\#} 1$, manual calculations of $f_{\mathrm{H}}$ from all the stored ECGs were performed. However, based on the results of Experiment ${ }^{\#} 1$, manual calculations of reported $f_{\mathrm{H}}$ in Experiments ${ }^{\#} 2$ and ${ }^{\#} 3$ were only performed when the fish's $f_{\mathrm{H}}$ was reported to be less than 15 beats per minute (bpm), greater than $85 \mathrm{bpm}$, and/or when the QI value for $f_{\mathrm{H}}$ was greater than 0 . To manually calculate $f_{\mathrm{H}}$ from the stored ECGs, the time between successive $\mathrm{R}$ wave peaks was measured (in seconds), these values were averaged, and then 60 was divided by the average to obtain the fish's $f_{\mathrm{H}}$ in bpm. Manual calculations of $f_{\mathrm{H}}$ were not possible when there was only one $\mathrm{PQRS}$ complex or when ECG artifacts made the PQRS complex unidentifiable, and these data were not included. For Experiment ${ }^{\#} 1$, heart rate variability (HRV) was also calculated as the standard deviation of the time between successive $\mathrm{R}$ wave peaks in milliseconds (ms) [24].

\section{Accelerometry parameters}

The centi-HRT ACT tag (with version 9 hardware) used in these studies stored acceleration values in three axes $(x, y$ and $z$ ) every second (i.e., at a frequency of $1 \mathrm{~Hz}$ ), this data provided by an accelerometer (ADXL346) with a resolution of $4 \mathrm{mg}$ (where $1000 \mathrm{mg}=1 \mathrm{~g}$, and $g$ is the acceleration of gravity or $9.8 \mathrm{~m} \mathrm{~s}^{-2}$ ). One $\mathrm{Hz}$ was the 
maximum recording frequency available of this version of the tag (range 0.067-1.0 Hz), and this frequency has previously been shown to provide strong relationships between accelerometry data, and swimming speed and metabolic rate [25].

Each logger was individually calibrated by Star-Oddi, a process in which each of the axes is rotated $360^{\circ}$ to derive the range of each axis under standard gravity. Static acceleration for each axis was then calculated using the following steps. First, the center of the range of values for each axis was measured and extracted from the raw accelerometer value, then each axis was normalized to $1 g$ based on the range measured for each axis during rotation. The algorithm then used this calibration information to separate the static and dynamic acceleration components of each measurement. The algorithm calculates EA as a vectorial sum of dynamic body acceleration, or VeDBA (reported by the software in $\mathrm{mg}$ ). In this study, the EA values presented were averaged over $1 \mathrm{~min}$. VAR is the variance in EA, calculated by the algorithm as the standard deviation of EA squared over a set sampling period (measured in $\mathrm{mg}^{2}$ ).

\section{Statistics}

In Experiment ${ }^{\#} 1$, linear mixed-effects models were used to determine the relationship between EA and swimming speed and TBF (fixed-effects), and between VAR and the latter two parameters (Additional file 1: Table S2). In this analysis, fish was included as a random factor, and the lowest Akaike information criterion was used to determine the best model (i.e., using a linear regression or log transformed data). Linear mixed-effects models were used to analyze the effect of swimming speed (fixedeffect) on $f_{\mathrm{H}}$, HRV and the percentage of $\mathrm{QI}_{0}$ data, with fish as a random factor.

For Experiments ${ }^{\#} 2$ and ${ }^{\#} 3$, linear mixed-effects models were also used to analyze $f_{\mathrm{H}}$, EA and the percentage of $\mathrm{QI}_{0}$ data. In Experiment ${ }^{\#} 2$, day-time/night-time and day post-surgery (day) were used as fixed-effects, there was an interaction term for the two parameters, and fish was used as a random factor. In Experiment ${ }^{\#} 3$, the same analysis was conducted with temperature included as a fixed-effect. A photoperiod of $12 \mathrm{~h}$ light: $12 \mathrm{~h}$ dark was maintained for both experiments, therefore photoperiod was assigned as 'day-time' between 8:00 a.m. and 7:59 p.m. or 'night-time' between 8:00 p.m. and 7:59 a.m. N1 was the first night following surgery, and the subsequent day-time and night-time values, respectively, were reported for day 1 (D1) through day 6 (D6) (Experiment ${ }^{*} 2$ ) or through D42 (Experiment ${ }^{\#} 3$ ). In the second trial of Experiment ${ }^{\#} 3$ ( $n=5$ per trial), the temperature in the tank fluctuated between 8 and $12{ }^{\circ} \mathrm{C}$ due to issues with facility temperature control, and thus, data for each trial were analyzed separately. In Experiment ${ }^{\#} 3$, data from every 10th day were used to identify differences in $f_{\mathrm{H}}$, EA and the percentage of $\mathrm{QI}_{0}$ between the day-time and night-time, and during recovery. In addition, to further investigate the number of days required for $f_{\mathrm{H}}$ to stabilize, day-time and night-time values for $f_{\mathrm{H}}$ up to D34 were compared to the average of the final week (W6) in the first trial of Experiment ${ }^{\#} 3$. Day-time/night-time and day were used as fixed-effects, with an interaction term for the two parameters, and fish was used as a random factor. In addition, a segmented regression was fitted to the data in Prism (Version 7; GraphPad Software, San Diego, CA, USA) to determine a break-point in the recovery data. These analyses were performed to estimate the day at which $f_{\mathrm{H}}$ stabilized post-surgery.

Linear mixed-effects models were produced in $\mathrm{R}$ version 3.5.1 [26] and RStudio version 1.2.1335 [27] with the nlme package [28]. For data analyzed in $\mathrm{R}$, assumptions of normality, homogeneity and independence were investigated by visual inspection of $\mathrm{Q}-\mathrm{Q}$ plots and histograms of the residuals, residual-fit plots and residual lag plots, respectively. The estimated marginal means, or emmeans, package [29] was used to perform Bonferroni's post-hoc tests on the linear mixed-effects models. Graphing of the data and statistical results was done using Prism software. The level of statistical significance was $P<0.05$. All values presented in the text, and in figures and tables, are means \pm standard errors of the mean (S.E.M).

\section{Results}

Relationship between accelerometry parameters and swimming speed

EA and VAR (as calculated by the tag algorithm) increased with both swimming speed and TBF $\left(\mathrm{EA}=3.6 e^{0.9 * \mathrm{BLs}^{-1}}\right.$ and $\mathrm{EA}=4.9 e^{0.006 * \mathrm{TBF}} ; \quad \mathrm{VAR}=5.0 e^{2.1 * \mathrm{BLs}^{-1}}$ and $\mathrm{VAR}=11.4 e^{0.01 * \mathrm{TBF}}:$ Fig. 2 ; Additional file 1: Table S2). EA ranged from $6.2 \mathrm{mg}$ at $0.6 \mathrm{BL} \mathrm{s}^{-1}$ to $15.2 \mathrm{mg}$ at 1.6 $\mathrm{BL} \mathrm{s}^{-1}$ (fold change $=2.45$ ), while VAR ranged from 17.6 to $143.9 \mathrm{mg}^{2}$ (fold change $=8.18$ ).

During the $U_{\text {crit }}$ test, $f_{\mathrm{H}}$ increased significantly from $61.1 \pm 1.0 \mathrm{bpm}$ at rest to $77.1 \pm 0.7 \mathrm{bpm}$ at $1.6 \mathrm{BL} \mathrm{s}^{-1}$ $(P<0.0001)$, while HRV decreased significantly from $62.4 \pm 3.6$ to $30.1 \pm 4.3 \mathrm{~ms}(P<0.0001)$ (Fig. 3; Additional file 1: Table S3). The percentage of good quality ECGs (i.e., $\mathrm{QI}_{0}$ ) did not change significantly with swimming speed $(P>0.05)$, but decreased marginally from $83 \%$ at rest to $\sim 60 \%$ while swimming. An average of $68 \%$ of the measurements were $\mathrm{QI}_{0}$ and only $0.1 \%$ of the total dataset could not be manually calculated after the experiments were completed (Table 2). The absolute difference in $f_{\mathrm{H}}$ between manually calculated values and those calculated by the tag algorithm increased with the reported QI value (i.e., $2.3 \pm 8.0 \mathrm{bpm}$ for $\mathrm{QI}_{0} ; 10.8 \pm 27.2 \mathrm{bpm}$ for 


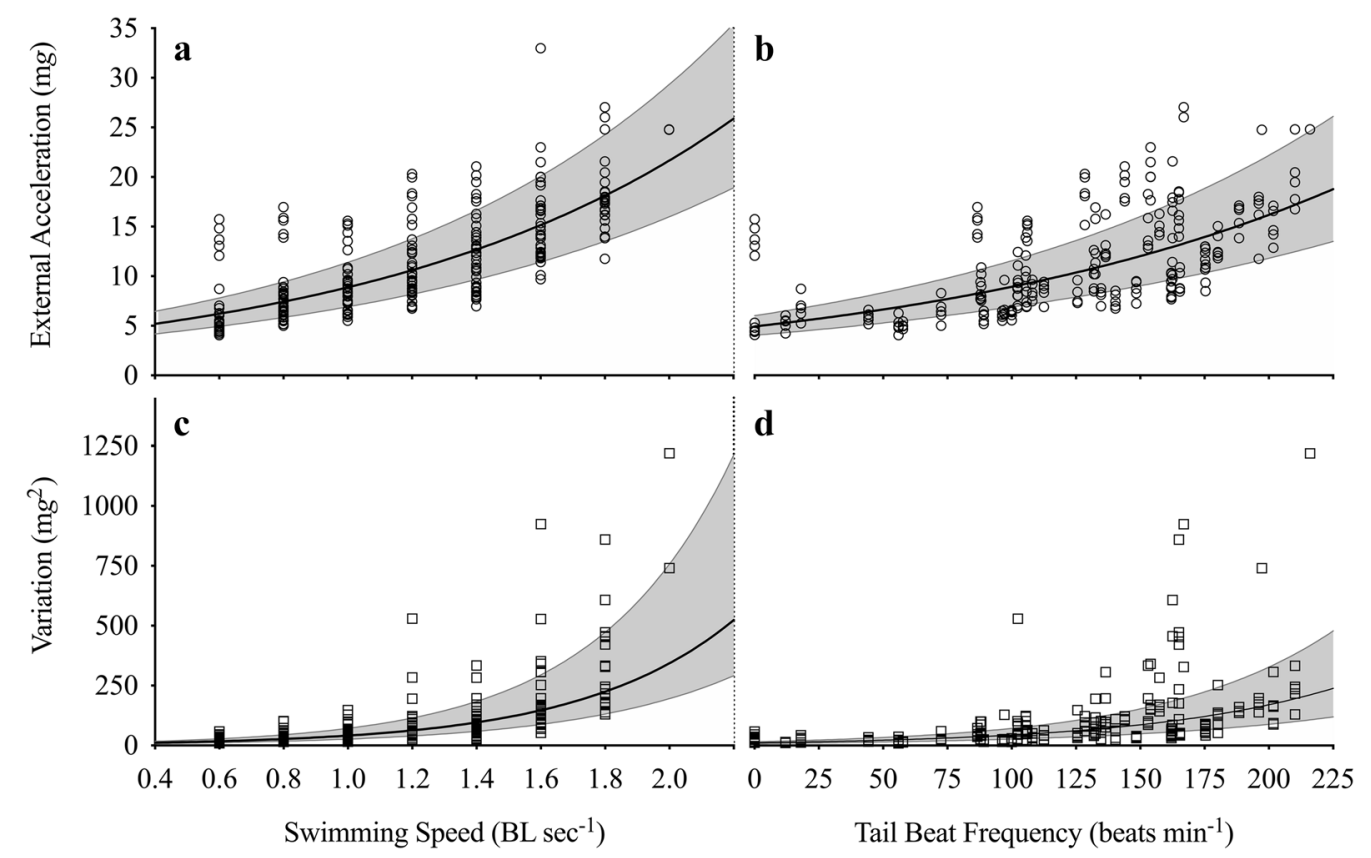

Fig. 2 External acceleration (EA) and variation in EA (VAR) measured in Atlantic salmon during a critical swim speed $\left(U_{\text {crit }}\right)$ test (water velocity increments of $0.2 \mathrm{BL} \mathrm{s}^{-1}$ ). Tail beat frequency (beats $\mathrm{min}^{-1}$ ) was determined from 30-s video clips recorded during each swimming speed. Linear mixed-effects models were fit to log transformed data and equation parameters were extracted as follows: $\mathbf{a} \mathrm{EA}=3.6 e^{0.9 * \mathrm{BL}}, \mathbf{b} \mathrm{BA}=4.9 e^{0.006 * \mathrm{TBF}}$, $\mathbf{c} \vee \mathrm{VAR}=5.0 e^{2.1 * \mathrm{BL}}$ and $\mathbf{d} \mathrm{VAR}=11.4 e^{0.01 * \mathrm{TBF}}$. Data are means \pm S.E.M.; $n=6$ to 8

$\mathrm{QI}_{1} ; 31.0 \pm 63.0 \mathrm{bpm}$ for $\mathrm{QI}_{2}$; and $39.5 \pm 41.2 \mathrm{bpm}$ for $\mathrm{QI}_{3}$; data not presented).

\section{Heart rate and activity during post-surgical recovery}

Following tag implantation, $f_{\mathrm{H}}$, EA, VAR and temperature were recorded in salmon recovering in their holding tanks with conspecifics for 1 week and 6 weeks (Fig. 4). Heart rate decreased $(P<0.0001)$ (Fig. 5; Additional file 1: Table S4), and EA increased $(P<0.0001)$, over the first week of recovery in Experiment ${ }^{\#} 2$; from $58.8 \pm 0.8$ and $47.4 \pm 0.9 \mathrm{bpm}$ (day-time and night-time values, respectively) initially to $43.9 \pm 0.7$ and $36.9 \pm 2.7 \mathrm{bpm}$ by the final day of recovery. In contrast, EA increased from $9.3 \pm 0.3 \mathrm{mg}$ in the day-time and $8.5 \pm 0.4 \mathrm{mg}$ in the nighttime ( 1.05 and $0.95 \mathrm{BL} \mathrm{s}^{-1}$ as estimated from swim tunnel calibrations) to $10.5 \pm 0.4$ and $9.6 \pm 0.4 \mathrm{mg}(\sim 1.19$ and $1.09 \mathrm{BL} \mathrm{s}^{-1}$ ). Based on a visual inspection of these data, it appeared that the measured parameters began stabilizing after approx. 4 days of recovery (Fig. 4a). However, significant differences were observed until the final day of recovery (day 7) (Fig. 5).

In the first trial of Experiment ${ }^{\#} 3$ at $8{ }^{\circ} \mathrm{C}, f_{\mathrm{H}}$ decreased until 21 days post-surgery when the data for every 10th day were analyzed (Fig. 6a; $P<0.0001$ ). However, the break-point analysis (using a segmented regression) found that night-time $f_{\mathrm{H}}$ reached a stable baseline by $\sim 17$ days (slope $1=-0.44$, slope $2=0.02$ ) and day-time $f_{\mathrm{H}}$ reached baseline values by $\sim 22$ days post-surgery (slope $1=-0.54$, slope $2=-0.001$; Fig. $7 \mathrm{a}$ ). This timeframe is a little longer than determined using the linear mixed-effects model analysis. In this analysis, $f_{\mathrm{H}}$ declined from initial values of $43.6 \pm 1.4$ and $31.2 \pm 1.4 \mathrm{bpm}$ until the 14th day, this the first day at which both day and night-time $f_{\mathrm{H}}$ were not significantly different from the averages for the final week $(30.6 \pm 0.6$ and $24.7 \pm 0.5 \mathrm{bpm}$; Fig. 7b). Collectively, these data indicate that it takes between 2 and 3 weeks for a salmon's $f_{\mathrm{H}}$ to stabilize after the implantation of the centi-HRT ACT tags.

Overall, salmon in this trial were less active (average $\mathrm{EA}=\sim 6.4 \mathrm{mg}$; or $0.62 \mathrm{BL} \mathrm{s}^{-1}$ ) than salmon held for 1 week of recovery (average $\mathrm{EA}=\sim 9.5 \mathrm{mg}$; or $1.04 \mathrm{BL} \mathrm{s}^{-1}$ ), and EA increased by $140 \%$ during the recovery period $(P<0.0001)$. Heart rate decreased and EA increased similarly in the second trial $(P<0.0001$ and $P<0.0001$, respectively). While temperature did not significantly affect $f_{\mathrm{H}}$ or EA $(P>0.05)$ when based on averages calculated every 10th day, fluctuations in temperature did alter the daily averages as compared to the first trial. For example, day-time $f_{\mathrm{H}}$ and EA on D21 were $\sim 8 \mathrm{bpm}$ and $\sim 1 \mathrm{mg}$ higher in the second trial (average temperature $9.3 \pm 0.1{ }^{\circ} \mathrm{C}$ ) than in the first trial 


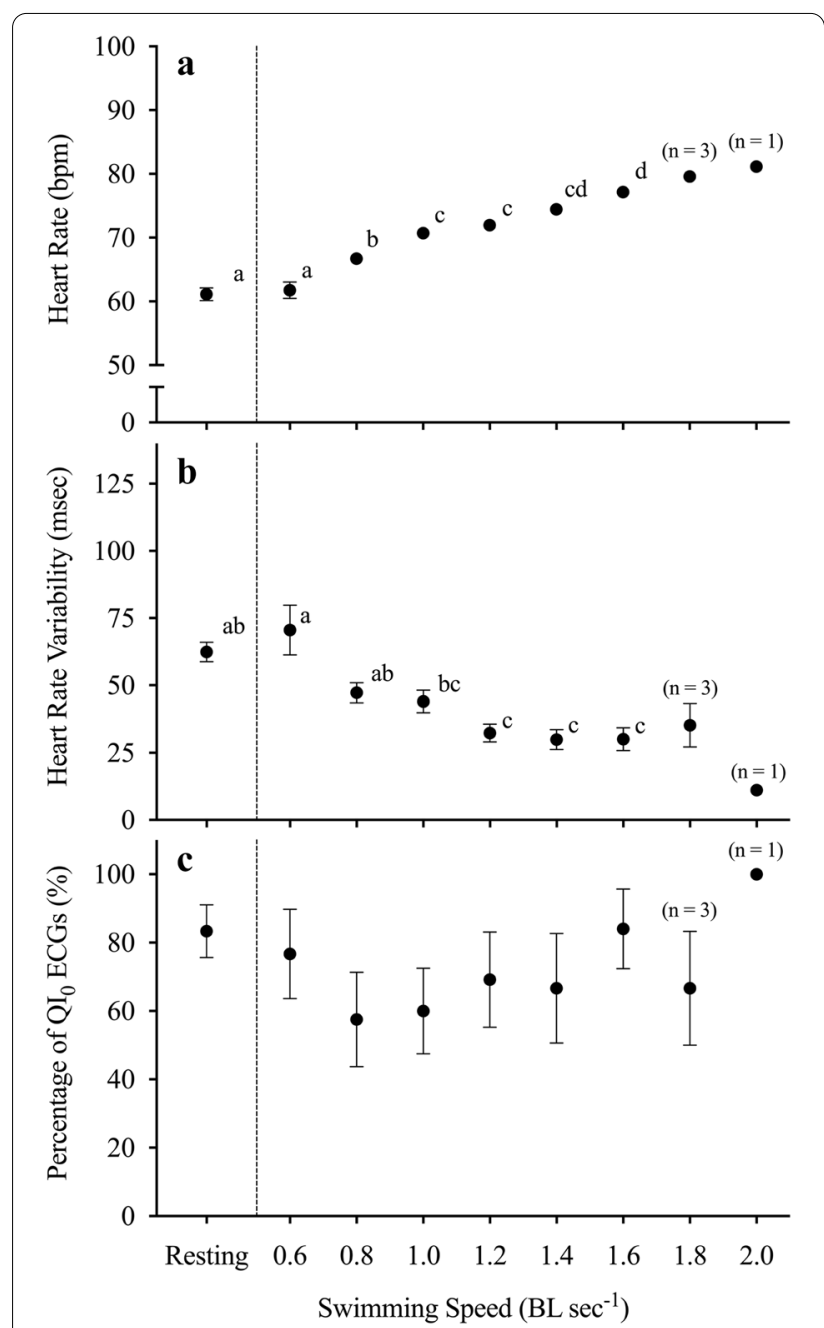

Fig. 3 Changes in heart rate $\left(f_{H}\right)$ and related parameters when Atlantic salmon were given a critical swim $\left(U_{\text {crit }}\right)$ test (water velocity increment of $0.2 \mathrm{BL} \mathrm{s}^{-1}$ ). $\mathbf{a} f_{\mathrm{H}}$ (in bpm) was measured every 2 min in salmon immediately prior to (resting values) and during the $U_{\text {crit }}$ test. Heart rate variability (HRV, in ms); $\boldsymbol{b}$ was manually calculated from the electrocardiograms and the percentage of 'good' quality ECGs (i.e., $\mathrm{Ql}_{0}$ ); c was calculated by the tag algorithm. Dissimilar lower case letters indicate a significant difference between values, as determined by linear mixed-effects models. These models did not include the swimming speeds of 1.8 and $2.0 \mathrm{BL} \mathrm{s}^{-1}$ due to low sample sizes. The percentage of good quality ECGs did not change significantly with swim speed $(P>0.05)$. Data are means \pm S.E.M.; $n=6-8$ except where indicated

$\left(8.1 \pm 0.0^{\circ} \mathrm{C}\right)$. Indeed, when the $f_{\mathrm{H}}$ data from the second trial (excluding data from the first week of recovery) were plotted against temperature, there was a significant relationship $\left(f_{\mathrm{H}}=3.01\right.$ * temperature $+2.64 ; \quad R^{2}=0.23$; $P<0.0001$; data not presented). When temperature was $8.5^{\circ} \mathrm{C} f_{\mathrm{H}}$ was on average $28.2 \mathrm{bpm}$, whereas at $12{ }^{\circ} \mathrm{C} f_{\mathrm{H}}$ averaged $38.8 \mathrm{bpm}$.

\section{Diel heart rate and activity patterns post-surgery}

The effects of photoperiod on $f_{\mathrm{H}}$ (i.e., diel variation) were consistent and significant in all recovery trials $(P<0.0001$; Figs. 5, 6, 7; Additional file 1: Tables S4, S5). Salmon held at $10-11{ }^{\circ} \mathrm{C}$ had day-time $f_{\mathrm{H}}$ values $\sim 7 \mathrm{bpm}$ higher than night-time values by 1 week post-surgery (Fig. 5), while at $8{ }^{\circ} \mathrm{C}$, average diurnal variation was $\sim 4 \mathrm{bpm}$ at 42 days. In salmon held at $10-11{ }^{\circ} \mathrm{C}$ for 1 week, photoperiod also had a significant effect on EA (a difference of $\sim 1 \mathrm{mg}$, $0.09 \mathrm{BL} \mathrm{s}^{-1}$ by 1 week post-surgery). However, there were no significant effects of photoperiod on EA during Trial 1 $\left(8{ }^{\circ} \mathrm{C}\right)$ or Trial $2\left(8-12{ }^{\circ} \mathrm{C}\right)$ when the salmon were recovered for 6 weeks $(P>0.05)$.

\section{Measurement quality and tag retention post-surgery}

The percentage of good quality ECG values decreased significantly (by $\sim 11 \%$ ) over the 1 week of recovery $(P=0.0002)$ (Fig. 5; Additional file 1: Table S4), but did not change significantly over the 6 weeks of recovery $(P>0.05)$ (Fig. 6c, d; Additional file 1: Table S5). There were also no significant diel patterns in ECG quality. Throughout Experiments ${ }^{\#} 2$ and ${ }^{\#} 3$, the average percentage of good quality ECGs (i.e., $\mathrm{QI}_{0}$ ) was $\sim 86$ and $88 \%$, and only a very small percentage of these $f_{\mathrm{H}}$ data could not be manually calculated from the ECGs $(\sim 2$ to $6 \%$; Table 2). Following 6 weeks of holding, all tags remained within $0.7 \mathrm{~cm}$ of the pericardium, $80 \%$ of the incisions were fully healed, and $80 \%$ of anterior anchor knots and $70 \%$ of posterior anchor knots were intact. However, only $10 \%$ of incision sutures remained. All milli-TD tags were still securely attached to the dorsal muscle of the salmon.

\section{Discussion}

Relationship between accelerometry parameters, heart rate and swimming speed

A goal of this paper was to establish whether significant relationships exist between the swimming speed of Atlantic salmon and the parameters of acceleration calculated by the tag algorithm. EA and VAR increased exponentially with swimming speed and TBF (Fig. 2), and the EA data were subsequently used to estimate the swimming speed of salmon in the large tanks. Previous researchers have also recorded relationships between swimming speed and/or TBF and acceleration [5, 8, 18, 19]. For example, Brownscombe et al. [25] reported swimming speed was linearly related to acceleration (calculated as overall dynamic body acceleration; ODBA) when measured at recording frequencies from 1 to $25 \mathrm{~Hz}$, and that at $1 \mathrm{~Hz}$ ODBA increased by approximately fivefold during a $U_{\text {crit }}$ test. Clark et al. [5] reported an exponential relationship between acceleration activity (calculated as the sum of the $X$ and $Y$ acceleration values with no specific 
Table 2 Distribution of QI values, and percentage of $f_{H}$ data that could not be manually calculated

\begin{tabular}{|c|c|c|c|c|c|}
\hline & Experiment & $\mathrm{QI}_{0}$ & $\mathrm{QI}_{1}$ & $\mathrm{QI}_{2}$ & $\mathrm{Ql}_{3}$ \\
\hline \multirow[t]{3}{*}{ Percentage of $f_{H}$ data } & $U_{\text {crit }}$ & $68.5 \pm 9.2$ & $13.1 \pm 4.2$ & $14.4 \pm 4.4$ & $3.9 \pm 1.8$ \\
\hline & Recovery (1 week) & $88.8 \pm 2.8$ & $5.4 \pm 2.2$ & $5.0 \pm 0.9$ & $0.9 \pm 0.3$ \\
\hline & Recovery (6 weeks) & $86.9 \pm 4.7$ & $3.5 \pm 2.1$ & $4.0 \pm 1.5$ & $5.6 \pm 3.7$ \\
\hline \multirow{3}{*}{$\begin{array}{l}\text { Percentage of } f_{H} \text { data that could not } \\
\text { be calculated }\end{array}$} & $U_{\text {crit }}$ & 0 & 0 & $1.7 \pm 0.9$ & $0.3 \pm 0.3$ \\
\hline & Recovery (1 week) & 0 & $0.1 \pm 0.1$ & $0.3 \pm 0.1$ & $0.1 \pm 0.0$ \\
\hline & Recovery (6 weeks) & $0.1 \pm 0.0$ & $0.4 \pm 0.4$ & $0.7 \pm 0.6$ & $4.7 \pm 3.5$ \\
\hline
\end{tabular}

The percentage of ECGs of each quality index value $\left(\mathrm{QI}_{0-3}\right)$, and the percentage of heart rate $\left(f_{\mathrm{H}}\right)$ values that could not be manually calculated, due to ECG artifacts during the $U_{\text {crit }}$ test $(n=8)$, during 1 week of recovery $(n=10)$, and during 6 weeks of recovery $(n=10)$

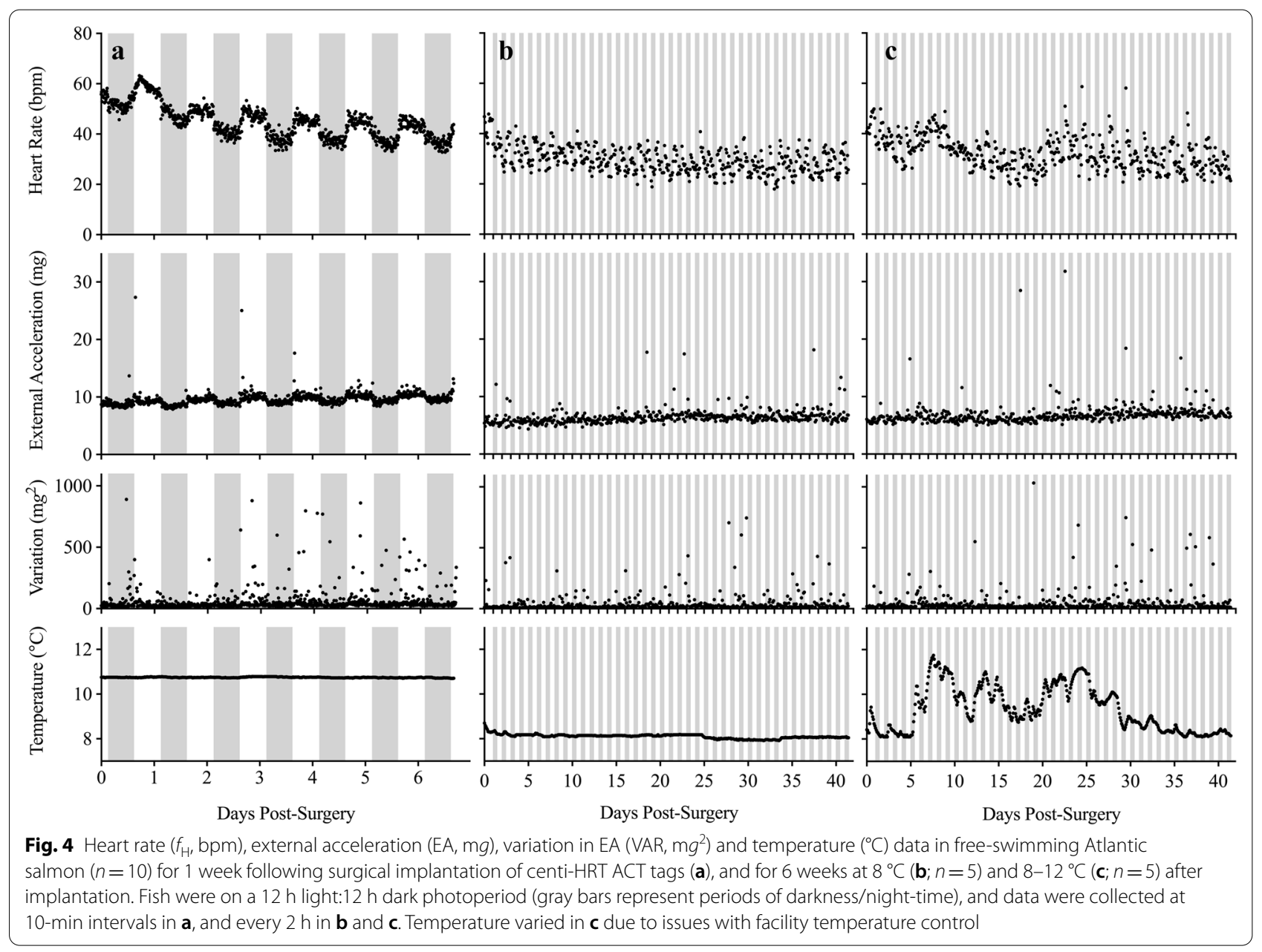

units) and TBF in sockeye salmon, and that there was a 7.2-fold change in acceleration activity from 40 to 170 tail beats $\min ^{-1}$. Similarly, Wright et al. [8] reported that an exponential equation was the best fit between measurements of VeDBA and swimming speed in European sea bass, Dicentrarchus labrax, with a 6.1-fold increase in VeDBA between 0.4 and $1.7 \mathrm{BL} \mathrm{s}^{-1}$. In contrast to the above studies, there was only a 2.5 -fold change in EA in our $U_{\text {crit }}$ test between salmon at rest and those swimming at $1.6 \mathrm{BL} \mathrm{s}^{-1}$. Despite this, the acceleration parameters as calculated by the tag algorithm (i.e., EA and VAR) were strongly related to salmon swimming speed.

Acceleration has often been related to metabolism, and used as a proxy for energy expenditure in freely swimming fish $[5,7,8,19,25]$. However, $f_{\mathrm{H}}$ is also highly correlated with metabolic rate in fish under most 


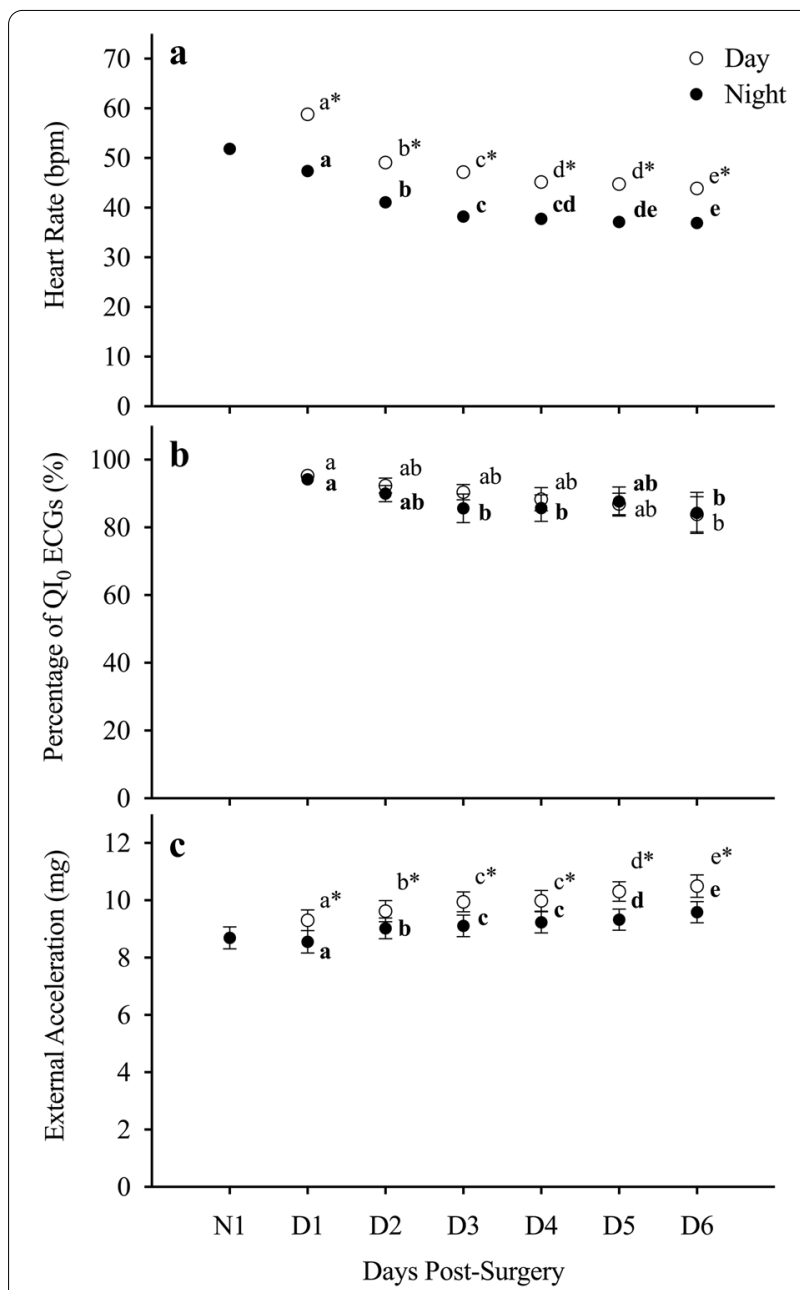

Fig. 5 Average day-time and night-time heart rate ( $f_{H}$ in bpm; a), percentage of 'good' quality ECG values (i.e., $\mathrm{QI}_{0} ; \mathbf{b}$ ) and external acceleration (EA in $\mathrm{mg} ; \mathbf{c}$ ) values in free-swimming Atlantic salmon $(n=10)$ recorded for 7 days following surgical implantation of the centi-HRT ACT tag. Open symbols represent day-time, whereas dark symbols represent periods of darkness/night-time. Dissimilar lower case letters indicate a significant difference within photoperiod (night-time values in bold), while an asterisk $\left(^{*}\right.$ ) represents a significance difference between day-time and night-time values at each measurement period. Data are means \pm S.E.M, with each value representing the average of $n=72$ data points per fish

circumstances ([30,31], but see [32]). The $f_{\mathrm{H}}$ of Atlantic salmon increased 1.26-fold during the swimming trial (i.e., from a resting value of $61 \mathrm{bpm}$ to $77 \mathrm{bpm}$ at 1.6 $\mathrm{BL} \mathrm{s}^{-1}$; Fig. 3). This is within the range of increases reported by other authors for adult salmonids during swimming trials (1.05- to 2.42-fold) [33-35]. Given the increase in $f_{\mathrm{H}}$ in this study, and the well-established relationship between metabolism and acceleration, it is likely that EA would correlate with oxygen consumption $\left(\dot{M O}_{2}\right)$ and that the centi-HRT ACT tags could be used as a tool to estimate the energy use of salmon in future studies. This, however, would require the establishment of a direct relationship between these parameters.

Further, the centi-HRT ACT tag provides the opportunity to save and analyze ECGs, and thus, investigate additional aspects of cardiac physiology. HRV (i.e., variation in the time between heart beats) is influenced by the autonomic nervous system and contains valuable information on functioning of the heart and fish physiology [24, 36, 37]. Studies quantifying HRV in fish are rare, probably due to the difficulty of recording ECGs for prolonged periods [37]. Although the $f_{\mathrm{H}}$ of salmon increased during the swim test, HRV decreased by approx. 52\% (from resting values of $62 \mathrm{~ms}$ to $30 \mathrm{~ms}$ at 1.6 $\mathrm{BL} \mathrm{s}^{-1}$; Fig. 3). Since beat-to-beat variability is known to be predominantly regulated by cholinergic innervation of the cardiac pacemaker [24], the decrease in HRV suggests enhanced parasympathetic control of $f_{\mathrm{H}}$ during the exhaustive swimming test.

A gait transition typically occurs in fish, from steady swimming at low speeds to burst-and-coast swimming at higher speeds approaching $U_{\text {crit }}$, and signifies a switch from aerobic to anaerobic energy metabolism [17, 38]. This transition is thought to provide energy savings and increase endurance at higher swimming speeds [39]. In adult salmonids, the transition to burst-and-coast swimming typically occurs between 1.6 and $2.2 \mathrm{BL} \mathrm{s}^{-1}$ (e.g., see $[19,40,41])$. We found that extremely high values of VAR (i.e., greater than $\sim 220 \mathrm{mg}^{2}$; Fig. 2) were recorded during periods of burst-and-coast swimming, which began after $\sim 1.6 \mathrm{BL} \mathrm{s}^{-1}$ in this group of salmon. Based on this information, we estimated that the salmon spent the vast majority of their time swimming steadily in the tank, with few periods of rapid/burst swimming $(2.8 \%$ of the time during Experiment ${ }^{\#} 2$, and $3.6 \%$ and $4.0 \%$ of the time during the two trials in Experiment ${ }^{\sharp} 3$ ).

\section{Heart rate and activity during post-surgical recovery}

The implantation of tags requires that procedures such as netting, handling and anesthesia be used, and that the fish undergo surgery, which are all known to be stressful on the fish being tagged [33, 37, 42]. Conveniently, the parameters being recorded by the centi-HRT ACT $\operatorname{tag}$ (i.e., $f_{\mathrm{H}}$ and activity) provide information about the impact of surgery and can help to establish recommendations for recovery time post-implantation. For instance, it is well known that $f_{\mathrm{H}}$ indicates the level of stress experienced by fish, and thus, it can be used to determine/ estimate recovery time following a variety of stressors (e.g., see $[9,15,42])$. In Experiment ${ }^{\#} 2$, it appeared that the salmon's $f_{\mathrm{H}}$ began to stabilize within the first 4 days following surgical implantation (Fig. 5). This timeframe is similar to that reported by Brijs et al. $[11,12]$ for the 


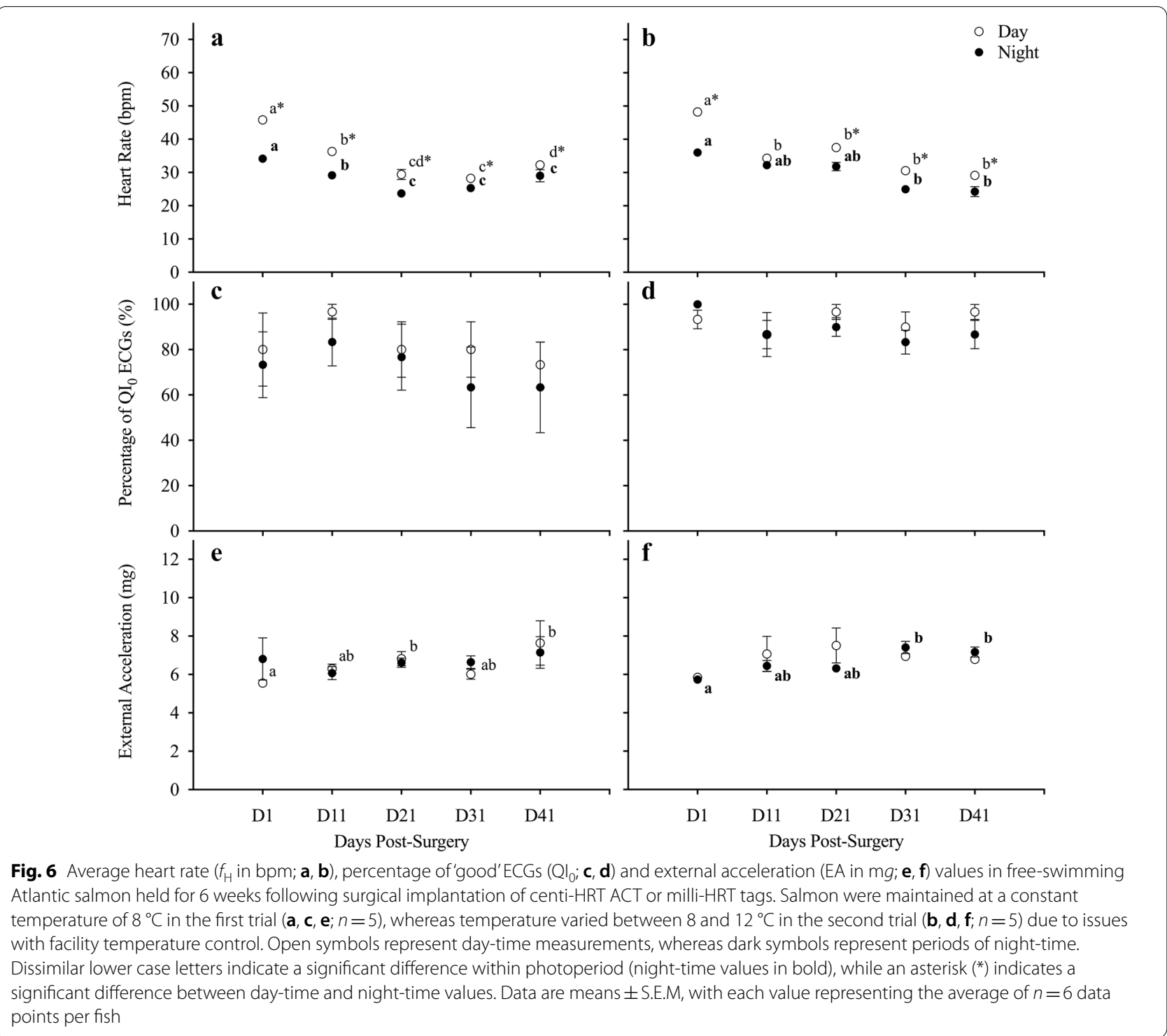

$f_{\mathrm{H}}$ of rainbow trout tagged with milli-HRT tags. However, when holding salmon for extended periods during Experiment ${ }^{\#} 3$, it was revealed that the $f_{\mathrm{H}}$ of the salmon continued to decline for up to 2-3 weeks (Fig. 7). The reason(s) for this prolonged recovery period is/are not known. However, these data are consistent with Hvas et al. [43], and recent data suggest that the presence of tags inside the body cavity induces a long-term immune response [44]. This latter finding may provide an explanation for the lengthy period required for $f_{\mathrm{H}}$ to achieve stable values.

In this study, diurnal variations in $f_{\mathrm{H}}$ were recorded in salmon immediately following surgery and they were maintained for the 7 and 42 day holding periods in Experiments ${ }^{\#} 2$ and ${ }^{\#} 3$, respectively (Figs. 5, 6, 7).
The mean difference in $f_{\mathrm{H}}$ between day-time and nighttime was $\sim 7 \mathrm{bpm}$ and the range of values over $24 \mathrm{~h}$ was $\sim 14 \mathrm{bpm}$ (Fig. 4). This latter value is very similar to the diurnal variation in $f_{\mathrm{H}}$ reported by Hvas et al. [43] for Atlantic salmon implanted with milli-HRT tags and held at $9{ }^{\circ} \mathrm{C}$. Conversely, Brijs et al. [11] reported that diel variations in $f_{\mathrm{H}}$ were not apparent until 3 days post-surgery in rainbow trout, and that the average daily fluctuation in $f_{\mathrm{H}}$ was $\sim 27 \mathrm{bpm}$. In Experiment ${ }^{\#} 2$, diurnal patterns in EA were present immediately following surgery and were maintained throughout the 1 week holding period at $10-11^{\circ} \mathrm{C}$ (Fig. 5). In contrast, there was no evidence of significant diel variations in EA when salmon were held for 6 weeks at $8-12{ }^{\circ} \mathrm{C}$ in Experiment ${ }^{\#} 3$ (Fig. 6). There are two possible explanations for the discrepancy in the 

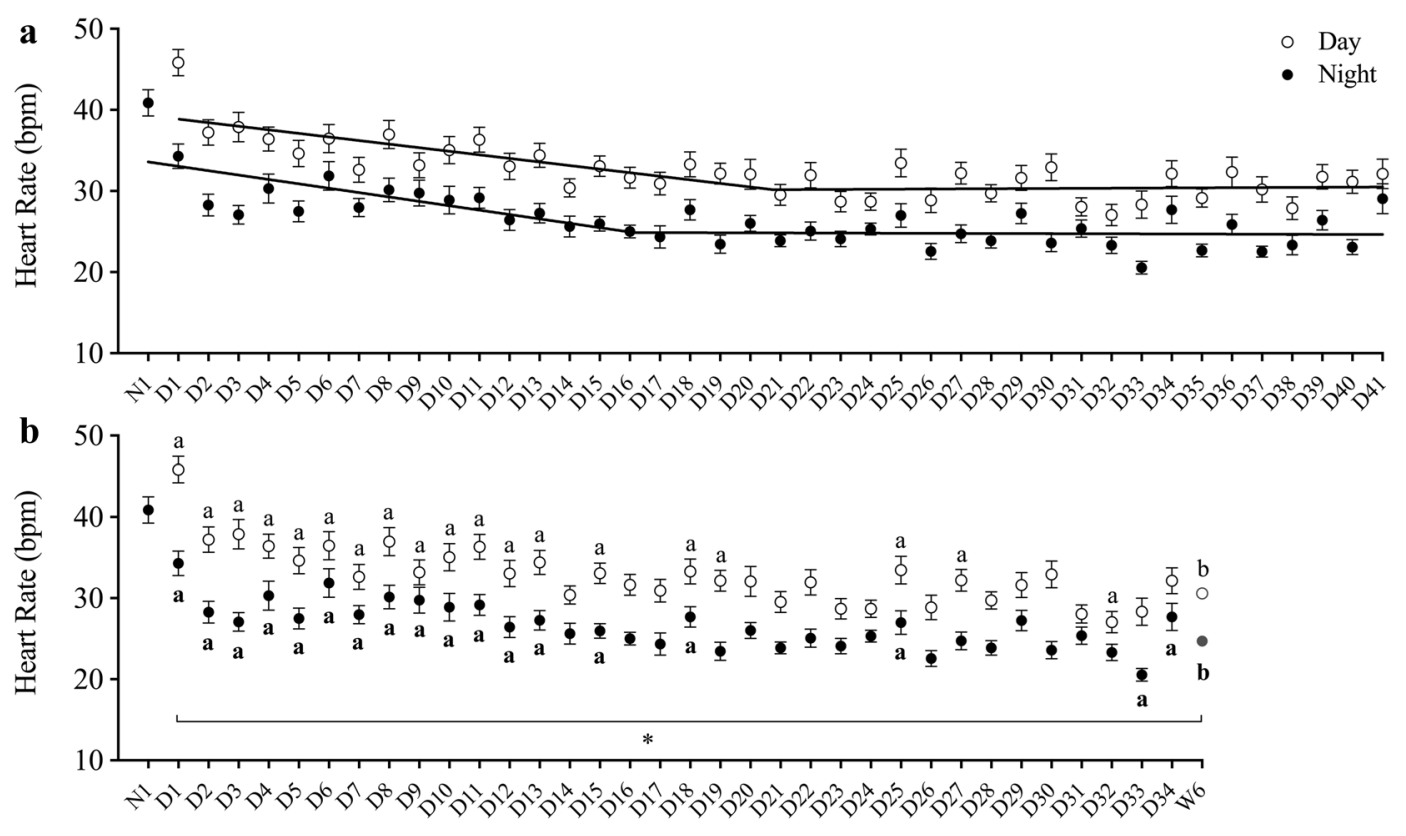

Days Post-Surgery

Fig. 7 Average heart rate ( $f_{H}$ in bpm) values in free-swimming Atlantic salmon held at $8{ }^{\circ} \mathrm{C}$ for 6 weeks following surgical implantation of centi-HRT ACT or milli-HRT tags. Open symbols represent day-time measurements, whereas dark symbols represent periods of night-time. a A segmented regression was fitted to the day-time and night-time $f_{\mathrm{H}}$ data, and the equations and break-points for these regressions were: $f_{\mathrm{H} 1}=-0.44 *$ day $+39.75, f_{\mathrm{H} 2}=0.016^{*}($ day -21.75$)+30.17$; break-point 21.75 days; and $f_{\mathrm{H} 1}=-0.54 *$ day $+34.13, f_{\mathrm{H} 2}=-0.01 *($ day -17.12$)+24.89 ;$ break-point 17.12 days. b Results from the linear mixed-effects model: a lower case 'a' indicates a significant difference from the final week of recovery (W6) (b) with night-time values in bold. The asterisk (*) indicates values that were significantly different between day-time and night-time values. Data are means \pm S.E.M, with each value representing the average of 6 data points per fish $(n=5)$

presence of diel patterns of activity. First, the tags were programmed to record less frequently in Experiment ${ }^{\#} 3$ than ${ }^{\#} 2$ to save memory and battery life during the 6-week holding period (i.e., every $2 \mathrm{~h}$ vs. $10 \mathrm{~min}$ or, 12 measurements per day for each fish vs. 144). This reduction in the frequency of data collection likely limited the tag's ability to detect diel variations in EA. If the goal of future research is to study such fine scale patterns in swimming/behavior, such as diel variations of activity in fish, it is imperative that researchers optimize their sampling rate given the length of experiment they intend to perform. Second, the two trials of Experiment ${ }^{*} 3$ were also conducted at colder temperatures, and the salmon were less active overall. For example, average EA was $9.5 \mathrm{mg}\left(1.04 \mathrm{BL} \mathrm{s}^{-1}\right)$ in Experiment ${ }^{\#} 2$, whereas it was only $\sim 6.4 \mathrm{mg}\left(0.62 \mathrm{BL} \mathrm{s}^{-1}\right)$ in the longer experiments.

\section{Considerations for tag use and future feasibility studies}

The modified implantation method used in this study was effective for recording $f_{\mathrm{H}}$ and acceleration in Atlantic salmon. In order to effectively record $f_{\mathrm{H}}$, the electrodes of $f_{\mathrm{H}}$ loggers and transmitters must remain close to the pericardium throughout deployment [45]. Therefore, we chose to suture the centi-HRT ACT tag to the body wall before closing the incision. This resulted in good quality ECG recordings during both the exhaustive exercise $\left(U_{\text {crit }}\right)$ protocol and the 1 and 6 weeks that the salmon were held in the large tanks; the average percentage of good quality ECGs (i.e., $\mathrm{QI}_{0}$ ) approximately 68, 86 and $88 \%$, respectively (Table 2 ). It has been reported that increased activity can interfere with ECG recordings due to potentials produced by the aerobic muscles [33]. However, this was very rare in these studies. There were only two instances when $f_{\mathrm{H}}$ that could not be calculated due to noisy signals corresponded with feeding activity. The positioning of the tag was also consistent with suggestions for implanting accelerometers, e.g., aligning the tag with the major plane of movement (i.e., the lateral movement of the tail) and placing the tags close to the animal's center of gravity [7]. Further, suturing the tags to the body wall would have reduced the potential for variation in logger position between individuals, which can impact the interpretation of accelerometry data [6].

While previous research has reported issues with the retention of internally implanted tags and the survival of tagged salmonids (e.g., see [46]), all tags were found 
in their original position and survival was $100 \%$ for the Atlantic salmon tagged in this study. It is important to acknowledge that tag retention, healing and survival inside a tank or hatchery setting may not be representative of fish tagged in the wild or in the sea-cage environment, and often varies between studies. For example, Føre et al. [47] experienced problems with tag ejection and mortality in sea-caged Atlantic salmon that were implanted with Star-Oddi micro-TD tags and released back into their cages on the same day as surgery. In contrast, rainbow trout tagged with milli-HRT tags, and recovered in a facility for 2 days before re-entering the sea-cage, experienced no mortality over 21 days [11]. While the tagging method used in the present study was effective for salmon held in a tank, and may hold true for other adult salmonids, experiments using different species or tag types/sizes may have varying results as effective tagging depends on a range of factors [48]. Therefore, it is strongly suggested that feasibility studies investigating tag retention and survival be performed prior to the extended use of biologgers.

Overall, the ECGs recorded in the Atlantic salmon were of good quality, and the $f_{\mathrm{H}}$ values recorded by the HRT ACT tags were highly sensitive (responsive) to biotic and abiotic changes. For example, the tags were able to detect increases in $f_{\mathrm{H}}$ with swimming speed (Fig. 3), diurnal changes in $f_{\mathrm{H}}$ (Fig. 5), and those associated with small changes in temperature. However, there were some issues with the quality of the recorded ECGs. During the critical swim speed test, $f_{\mathrm{H}}$ was sometimes miscalculated by as much as $39 \mathrm{bpm}$ by the tag algorithm when ECGs were of poor quality $\left(\mathrm{QI}_{>0}\right)$. Due to this concern, Prystay et al. $[9,10]$, Brijs et al. [11, 12] and Wallerius et al. [13] chose a highly conservative approach, and removed all poor quality $f_{\mathrm{H}}$ values $(\mathrm{QI}>0)$. However, we chose to either manually calculate $f_{\mathrm{H}}$ from all of the ECGs, or just those of poor quality, and as a result, very few data points had to be removed from each experiment (less than 1\%). We highly recommend that users of Star-Oddi $f_{\mathrm{H}}$ loggers prioritize saving and inspecting ECGs prior to data analysis and interpretation. Using our operational settings, a centiHRT ACT tag with a full battery can record $f_{\mathrm{H}}$, acceleration and temperature at a 2-h sampling frequency for 230 days when all ECGs are saved, whereas the length of sampling is extended to 455 and 1838 days when $50 \%$ or no ECGs are saved, respectively.

Research using non-invasive and un-tethered $f_{\mathrm{H}}$ recording methods, including this paper, have measured the lowest resting $f_{\mathrm{H}}$ values in salmonids $(\sim 20$ to $37 \mathrm{bpm})[5,15,33,37,43]$. However, our research and that of Brijs et al. [12] report that Star-Oddi $f_{\mathrm{H}}$ loggers were limited in their ability to record low resting $f_{\mathrm{H}}$ values due to the maximum sampling and recording periods permitted by the manufacturer (i.e., 600 measurements per sampling period; $100 \mathrm{~Hz}$ for $6 \mathrm{~s}$ ). This is because, at $f_{\mathrm{H}}$ values $<20 \mathrm{bpm}$, the R-R interval is longer than the $6 \mathrm{~s}$ recording period. As mentioned in Brijs et al. [12], an update to the centi-HRT ACT tags now allows the user to record ECGs for longer periods, and with up to 1500 measurements per sampling (i.e., at $80 \mathrm{~Hz}$ for $18.8 \mathrm{~s}$, $100 \mathrm{~Hz}$ for $15 \mathrm{~s}$, or $125 \mathrm{~Hz}$ for $12.5 \mathrm{~s}$ ), and this should allow research to be conducted on cold water species and throughout the winter months. However, users should be aware that the ability to sample $f_{\mathrm{H}}$ over prolonged periods is a tradeoff with increased battery consumption and memory usage when choosing to save ECGs.

Debate exists over the sampling frequency required when using acceleration to determine the behavior of animals [19]. We used a lower sampling frequency $(1 \mathrm{~Hz}$ for $60 \mathrm{~s}$ every $2 \mathrm{~min}, 10 \mathrm{~min}$ or $2 \mathrm{~h}$ ) which has been referred to as discrete or burst/epoch sampling [17]. In this study, this lower frequency was useful in estimating the swimming speed of Atlantic salmon, and can indicate when salmon are burst-and-coast swimming. Similarly, Brownscombe et al. [25] reported that ODBA recorded at $1 \mathrm{~Hz}$ was significantly related to swimming speed and $\mathrm{MO}_{2}$, and Wilson et al. [19] found that a frequency of $10 \mathrm{~Hz}$ for $10 \mathrm{~s}$ could be used to effectively estimate swimming speed and $\mathrm{MO}_{2}$ in sockeye salmon. Low frequency sampling allows for the characterization of one behavior type at a certain point in time, and can utilize fixed-threshold manual behavior referencing (e.g., [18, 49]). However, the continuous recording of micro-behaviors (i.e., those defining detailed animal behaviors) requires a higher sampling frequency [17].

Based on signal-processing theory, it has been suggested that sampling rate should be at least twice the highest frequency of the waveform being measured [17, 50]. In this research, we determined that the maximum TBF of Atlantic salmon of this size was approx. $3.5 \mathrm{~Hz}$. However, we recommend that researchers perform preliminary tests to determine the most effective sampling frequency for their species. Such recordings require significant memory and battery life, and thus, discrete sampling is a valuable option depending on a user's research objectives.

\section{Conclusions}

There is a growing need for validation/feasibility studies prior to the use of biologgers [51], especially those that record multiple parameters or when they are being used in previously untagged or rarely tagged species. Physiological sensors are currently underutilized, but could be an extremely useful tool for advancing fish welfare and conservation efforts. For example, the $f_{\mathrm{H}}$ loggers used in this study recorded good quality ECGs, provided quite 
accurate measurements of $f_{\mathrm{H}}$ in free-swimming salmon, and could record small changes in $f_{\mathrm{H}}$ associated with exercise, diel variation and changes in temperature. Using these DSTs, we found that salmon require a minimum of 4 days, and up to 2-3 weeks (consistent with Hvas et al. [43]), for $f_{\mathrm{H}}$ to stabilize following the surgical and implantation procedures required. In addition, the tags allowed for the quantification of HRV in the salmon during a $U_{\text {crit }}$ test, and thus, provide a new avenue for research on cardiac physiology. Lastly, the centi-HRT ACT tags recorded values of acceleration that can be used to estimate salmon swimming speed and TBF, and are useful for determining when salmon are swimming steadily or burst swimming. It is our hope that future users of these DSTs, and other biologgers, will find the data and recommendations provided in this paper useful.

\section{Supplementary Information}

The online version contains supplementary material available at https://doi. org/10.1186/s40317-021-00235-1.

Additional file 1: Figure S1. Milli-TD DSTs (that record depth and temperature) were attached to the fish externally using a "plate holder kit" provided by Star-Oddi and stainless steel wire ( 0.02 " diameter). Tags were prepared for attachment by looping pre-sterilized stainless steel wire over the tag and passing the ends of the wire through one of the kit's silicone pads and the pre-drilled holes in the kit's plastic mold. Four pre-sterilized stainless steel hypodermic needles (15 gauge, $3.5^{\prime \prime}$ long) were then passed through the skin and muscle below the dorsal fin to allow the stainless steel wire to be guided through. Then, the hypodermic needles were removed and the 4 wires exiting the muscle were passed through the kit's other silicone pad and plastic mold, and the wires were twisted together to secure the DST to the fish. Figure S2. An electrocardiogram (ECG) recorded in a salmon during 1 week of recovery. The ECG was randomly chosen to represent the typical recording from a salmon, where Bin ECG represents the amplitude of the PQRS waveform and ranges from 0 to $1000 \mathrm{mV}$. Heart rate $\left(f_{H}\right)$ was calculated from the ECGs as the time between $\mathrm{R}$ wave peaks (measured in seconds). These values were then averaged, and 60 was divided by the average to obtain the fish's $f_{H}$ in bpm. Heart rate variability (HRV) was calculated as the standard deviation of the time between successive R wave peaks (in ms). Table S1. Photographs of the Star-Oddi data storage tags used in this paper. Further information on these products can be found at https://www.star-oddi.com. Table S2. Linear mixed-effects models were used to determine the relationships between external acceleration (EA, $\mathrm{mg}$ ) and swimming speed $\left(\mathrm{BL} \mathrm{s}{ }^{-1}\right)$ and tail beat frequency (tail beats $\mathrm{min}^{-1}$ ), and between the latter two parameters and variation in EA $\left(V A R, \mathrm{mg}^{2}\right)$, with fish as a random factor. The lowest Akaike information criterion (AIC) value was used to select between the two models (linear regression and log transformed data). Table S3. Summary of the statistical outputs from linear mixed-effects models that were used to examine the effects of swimming speed on heart rate parameters in Atlantic salmon. Linear mixed-effects models were used to assess the effects of swimming speed (body lengths $\mathrm{s}^{-1}$ ) on heart rate, heart rate variability and the percentage of quality index values equal to zero $\left(\mathrm{Q} \mathrm{I}_{0}\right)$. Significant differences are shown in bold font. Table S4. Summary of the statistical outputs from the linear mixed-effects models that examined the effects of night/day (photoperiod), days post-implantation, and their interaction, on $f_{H}$ parameters $\left[f_{H}\right.$ and percentage of quality index values equal to zero $\left.\left(\mathrm{QI}_{0}\right)\right]$ and external acceleration (EA) in salmon for 7 days post-surgery. Significant differences are shown in bold. Table S5. Summary of the statistical output from the linear mixed-effects models that examined the effects of night/day (photoperiod), at every 10 days or for all days post-implantation, on $f_{H}$ parameters $\left[f_{H}\right.$ and percentage of quality index values equal to zero $\left.\left(\mathrm{Q} \mathrm{I}_{0}\right)\right]$ and external acceleration (EA) in Atlantic salmon for 6 weeks post-implantation, and their interaction. Due to issues with facility temperature control, the data is separated into two trials with a tank temperature of $8{ }^{\circ} \mathrm{C}$ in trial 1 (a 10 days; $\mathbf{b}$ all data) and $8-12^{\circ} \mathrm{C}$ in trial $2(\mathbf{c})$.

\section{Abbreviations}

ACT: Activity; BL: Body lengths; bpm: Beats per minute; COM-BOX: Star-Oddi Tag-Computer Interface; DST: Data storage tag; EA: External acceleration; ECG: Electrocardiogram; $f_{H}$ : Heart rate; HRT: Heart rate; HRV: Heart rate variability; $\dot{\mathrm{M}} \mathrm{O}_{2}$ : Oxygen consumption; MS-222: Tricaine methanesulfonate; ODBA:

Overall dynamic body acceleration; PQRS: Cardiac electrical activity associated with atrial and ventricular contraction; QI: Quality index; S.E.M.: Standard error of the mean; TBF: Tail beat frequency; $U_{\text {crit: }}$ Critical swim speed; VAR: Variation in external acceleration; VeDBA: Vectorial sum of dynamic body acceleration.

\section{Acknowledgements}

We thank Danny Boyce, Jessica Fry, Jennifer Monk and the staff of the Dr. Joe Brown Aquatic Research Building, and Ellen Peroni and Rebeccah Sandrelli, for assistance with fish care. A special thanks to Asgeir Bjarnason from Star-Oddi for providing technical information/specifications on the centi-HRT ACT tags, and to Albin Gräns for providing unpublished data and for fruitful discussions with regards to the use of Star-Oddi DSTs. Finally, we would like to thank the two anonymous reviewers for their helpful and insightful comments.

\section{Authors' contributions}

AKG conceptualized and designed the study and sourced funding. ZZ acquired, analyzed and interpreted the data. ZZ produced initial drafts of the paper and AKG made substantial contributions with regards to editing and data interpretation. Both authors read and approved the final manuscript.

\section{Funding}

The research described above is part of the Mitigating the Impacts of ClimateRelated Challenges on Salmon Aquaculture (MICCSA) project, and was funded by the Atlantic Canada Opportunities Agency (781-9658-205222), Innovate NL (5404-1209-104) and Innovate PEI. ZZ was also supported by a Memorial University School of Graduate Studies fellowship.

\section{Availability of data and materials}

The datasets used and/or analyzed during the current study are available from the corresponding author upon request.

\section{Ethics approval and consent to participate}

The Atlantic salmon used in the studies were supplied by the Dr. Joe Brown Aquatic Research Building at the Memorial University. All experimental work described was approved by the Institutional Animal Care Committee of

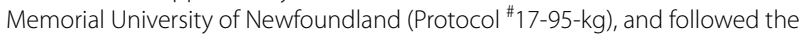
standards and guidelines outlined by the Canadian Council on Animal Care.

\section{Consent for publication}

All the authors have given final approval of the version to be published.

\section{Competing interests}

The authors declare that they have no competing interests.

Received: 20 August 2020 Accepted: 11 February 2021

Published online: 12 March 2021

\section{References}

1. Wilson RP, Shepard ELC, Liebsch N. Prying into the intimate details of animal lives: use of a daily diary on animals. Endag Species Res. 2008:4:123-37.

2. Metcalfe J, Wright S, Tudorache C, Wilson RP. Recent advances in telemetry for estimating the energy metabolism of wild fishes. J Fish Biol. 2016;88(1):284-97.

3. Ropert-Coudert Y, Wilson RP. Trends and perspectives in animal-attached remote sensing. Front Ecol Environ. 2005;3(8):437-44. 
4. Rutz C, Hays GC. New frontiers in biologging science. Biol Lett. 2009;5(3):289-92.

5. Clark TD, Sandblom E, Hinch SG, Patterson DA, Frappell PB, Farrell AP. Simultaneous biologging of heart rate and acceleration, and their relationships with energy expenditure in free-swimming sockeye salmon (Oncorhynchus nerka). J Comp Physiol B. 2010;180(5):673-84.

6. Halsey LG, Shepard ELC, Quintana F, Laich AG, Green JA, Wilson RP. The relationship between oxygen consumption and body acceleration in a range of species. Comp Biochem Phys A. 2009;152(2):197-202.

7. Gleiss AC, Dale JJ, Holland KN, Wilson RP. Accelerating estimates of activity-specific metabolic rate in fishes: testing the applicability of acceleration data-loggers. J Exp Mar Biol Ecol. 2010;385(1-2):85-91.

8. Wright $S$, Metcalfe JD, Hetherington S, Wilson R. Estimating activityspecific energy expenditure in a teleost fish, using accelerometer loggers. Mar Ecol Prog Ser. 2014;496:19-32.

9. Prystay TS, Eliason EJ, Lawrence MJ, Dick M, Brownscombe JW, Patterson DA, Crossin GT, Hinch SG, Cooke SJ. The influence of water temperature on sockeye salmon heart rate recovery following simulated fisheries interactions. Conserv Physiol. 2017;5(1):1-12.

10. Prystay TS, Lawrence MJ, Zolderdo AJ, Brownscombe JW, de Bruijn R, Eliason EJ, Cooke SJ. Exploring relationships between cardiovascular activity and parental care behavior in nesting smallmouth bass: a field study using heart rate biologgers. Comp Biochem Physiol A. 2019;234:18-27.

11. Brijs J, Sandblom E, Axelsson M, Sundell K, Sundh H, Huyben D, Broström R, Kiessling A, Berg C, Gräns A. The final countdown: continuous physiological welfare evaluation of farmed fish during common aquaculture practices before and during harvest. Aquaculture. 2018:495(1):903-11.

12. Brijs J, Sandblom E, Rosengren M, Sundell K, Berg C, Axelsson M, Gräns A. Prospects and pitfalls of using heart rate bio-loggers to assess the welfare of rainbow trout (Oncorhynchus mykiss) in aquaculture. Aquaculture. 2019:509(1):188-97.

13. Wallerius ML, Gräns A, Koeck B, Berger D, Sandblom E, Ekstrom A, Arlinghaus $\mathrm{R}$, Johnsson Jl. Socially induced stress and behavioural inhibition in response to angling exposure in rainbow trout. Fish Manag Ecol. 2019:00:1-10.

14. Ropert-Coudert Y, Kato A, Gremillet S, Crenner F. Biologging: recording the ecophysiology and behaviour of animals moving freely in their environment. In: Le Galliard J, Guarini K, Gaill F, editors. Sensors for ecology: towards integrated knowledge ecosystems. Paris: The French National Center for Scientific Research (CNRS); 2012. p. 43-62.

15. Donaldson MR, Clark TD, Hinch SG, Cooke SJ, Patterson DA, Gale MK, Frappell PB, Farrell AP. Physiological responses of free-swimming adult Coho salmon to simulated predator and fisheries encounters. Physiol Biochem Zool. 2010;83(6):973-83.

16. Algera DA, Brownscombe JW, Gilmour KM, Lawrence MJ, Zolderdo AJ, Cooke SJ. Cortisol treatment affects locomotor activity and swimming behaviour of male smallmouth bass engaged in paternal care: a field study using acceleration biologgers. Physiol Behav. 2017;181:59-68.

17. Brown DD, Kays R, Wikelski M, Wilson R, Klimley AP. Observing the unwatchable through acceleration logging of animal behaviour. Anim Biotelemetry. 2013;1(1):20.

18. Kawabe R, Kawano T, Nakano N, Yamashita N, Hiraishi T, Naito Y. Simultaneous measurement of swimming speed and tail beat activity of free-swimming rainbow trout Oncorhynchus mykiss using an acceleration data-logger. Fish Sci. 2003;69(5):959-65.

19. Wilson SM, Hinch SG, Eliason EJ, Farrell AP, Cooke SJ. Calibrating acoustic acceleration transmitters for estimating energy use by wild adult Pacific salmon. Comp Biochem Phys A. 2013;164(3):491-8.

20. Brownscombe JW, Thiem JD, Hatry C, Cull F, Haak CR, Danylchuk AJ, Cooke SJ. Recovery bags reduce post-release impairments in locomotory activity and behavior of bonefish (Albula spp.) following exposure to angling-related stressors. J Exp Mar Bio Ecol. 2013;440:207-15.

21. Yasuda T, Komeyama K, Kato K, Mitsunaga Y. Use of acceleration loggers in aquaculture to determine net-cage use and field metabolic rates in red sea bream Pagrus major. Fish Sci. 2012;78(2):229-35.

22. Ekström A, Axelsson M, Gräns A, Brijs J, Sandblom E. Importance of the coronary circulation for cardiac and metabolic performance in rainbow trout (Oncorhynchus mykiss). Biol Lett. 2018;14(7):1-4.

23. Lacroix GL, Know D, McCurdy P. Effects of implanted dummy acoustic transmitters on juvenile Atlantic salmon. Trans Am Fish Soc. 2004:133(1):211-20
24. Campbell HA, Taylor EW, Egginton S. The use of power spectral analysis to determine cardiorespiratory control in the short-horned sculpin Myoxocephalus scorpius. J Exp Biol. 2004;207:1969-76.

25. Brownscombe JW, Lennox RJ, Danylchuk AJ, Cooke SJ. Estimating fish swimming metrics and metabolic rates with accelerometers: the influence of sampling frequency. J Fish Biol. 2018;93(2):207-14.

26. R Core Team. R: a language and environment for statistical computing. Vienna, Austria: R Foundation for Statistical Computing; 2017. https:// www.r-project.org/.

27. RStudio Team. RStudio: integrated development for R. Boston, Massachusetts: RStudio Inc.; 2015. http://www.rstudio.com.

28. Pinheiro J, Bates D, DebRoy S. nlme: linear and nonlinear mixed effects models. R package version 3.1-148. 2020. https://cran.r-project.org/ package $=$ nlme

29. Singmann $H$, Hervé $M$, Love J, Buerkner P. emmeans: estimating marginal means, aka least-square means. R package version 1.3.4. 2019. https://github.com/rvlenth/emmeans.

30. Armstrong JD. Heart rate as an indicator of activity, metabolic rate, food intake and digestion in pike, Esox lucius. J Fish Biol. 1986:29:207-21.

31. Lucas MC. Heart rate as an indicator of metabolic rate and activity in adult Atlantic salmon, Salmo salar. J Fish Biol. 1994;44(5):889-903.

32. Thorarensen H, Gallaugher PE, Farrell AP. The limitations of heart rate as a predictor of metabolic rate in fish. J Fish Biol. 1996;49(2):226-36.

33. Altimiras J, Larsen E. Non-invasive recording of heart rate and ventilation rate in rainbow trout during rest and swimming. Fish go wireless! J Fish Biol. 2000;57(1):197-209.

34. Steinhausen MF, Sandblom E, Eliason EJ, Verhille C, Farrell AP. The effect of acute temperature increases on the cardiorespiratory performance of resting and swimming sockeye salmon (Oncorhynchus nerka). J Exp Biol. 2008:211(24):3915-26.

35. Eliason EJ, Clark TD, Hinch SG, Farrell AP. Cardiorespiratory collapse at high temperature in swimming adult sockeye salmon. Conserv Physiol. 2013;1 (1):cot008

36. Jeanne M, Logier R, De Jonckheere J, Tavernier B. Heart rate variability during total intravenous anesthesia: effects of nociception and analgesia. Auton Neurosci. 2009;147:91-6.

37. Gräns A, Sandblom E, Kiesslin A, Axelsson M. Post-surgical analgesia in rainbow trout: is reduced cardioventilatory activity a sign of improved animal welfare or the adverse effects of an opioid drug? PLOS ONE. 2014;9(4):e95283.

38. Peake SJ, Farrell AP. Locomotory behaviour and post-exercise physiology in relation to swimming speed, gait transition, and metabolism in free-swimming smallmouth bass (Micropterus dolomieus). J Exp Biol. 2004;207(9):1563-75.

39. Videler JJ, Weihs D. Energetic advantages of burst-and-coast swimming of fish at high speeds. J Exp Biol. 1982:97(1):169-78.

40. Lee CG, Farrell AP, Lotto A, MacNutt MJ, Hinch SG, Healey MC. The effect of temperature on swimming performance and oxygen consumption in adult sockeye (Oncorhynchus nerka) and coho (O. kisutch) salmon stocks. J Exp Biol. 2003;206(18):3239-51.

41. Hvas M, Folkedal O, Imsland A, Oppedal F. The effect of thermal acclimation on aerobic scope and critical swimming speed in Atlantic salmon, Salmo salar. J Exp Biol. 2017;220(15):2757-64.

42. Raby GD, Clark TD, Farrell AP, Patterson DA, Bett NN, Wilson SM, Willmore WG, Suski CD, Hinch SG, Cooke SJ. Facing the river gauntlet: understanding the effects of fisheries capture and water temperature on the physiology of coho salmon. PLoS ONE. 2015;10(4):e0124023.

43. Hvas M, Folkedal O, Oppedal F. Heart rate bio-loggers as welfare indicators in Atlantic salmon (Salmo salar). Aquaculture. 2020;529:735630.

44. Semple SL, Mulder IM, Rodriguez-Ramos T, Power M, Dixon B. Longterm implantation of acoustic transmitters induces chronic inflammatory cytokine expression in adult rainbow trout (Oncorhynchus mykiss). Vet Immunol Immunopathol. 2018:205:1-9.

45. Cooke SJ, Brownscombe JW, Raby GD, Broell F, Hinch SG, Clark TD, Semmens JM. Remote bioenergetics measurements in wild fish: opportunities and challenges. Comp Biochem Physiol A. 2016;202:23-37.

46. Ivasauskas TJ, Bettoli PW, Holt T. Effects of suture material and ultrasonic transmitter size on survival, growth, wound healing, and tag expulsion in rainbow trout. Trans Am Fish Soc. 2012;141(1):100-6. 
47. Føre M, Frank K, Dempster T, Alfredsen JA, Høy E. Biomonitoring using tagged sentinel fish and acoustic telemetry in commercial salmon aquaculture: a feasibility study. Aquac Eng. 2017;78:163-72.

48. Cooke SJ, Woodley CM, Eppard MB, Brown RS, Nielson JL. Advancing the surgical implantation of electronic tags in fish: a gap analysis and research agenda based on a review of trends in intracoelomic tagging effects studies. Rev Fish Biol Fish. 2011;21(1):127-51.

49. Tsuda Y, Kawabe R, Tanaka H, Mitsunaga Y, Hiraishi T, Yamamoto K, Nashimoto K. Monitoring the spawning behaviour of chum salmon with an acceleration data logger. Ecol Freshw Fish. 2006;15(3):264-74.
50. Yost M, Cooper RA, Bremner FJ. Fourier analyses: a mathematical and geometric explanation. Behav Res Methods Inst. 1983;15(2):258-61.

51. Wilson ADM, Wikelski M, Wilson RP, Cooke SJ. Utility of biological sensor tags in animal conservation. Conserv Biol. 2015;29(4):1065-75.

\section{Publisher's Note}

Springer Nature remains neutral with regard to jurisdictional claims in published maps and institutional affiliations.
Ready to submit your research? Choose BMC and benefit from:

- fast, convenient online submission

- thorough peer review by experienced researchers in your field

- rapid publication on acceptance

- support for research data, including large and complex data types

- gold Open Access which fosters wider collaboration and increased citations

- maximum visibility for your research: over 100M website views per year

At BMC, research is always in progress.

Learn more biomedcentral.com/submissions 